\title{
No adverse effect of a maternal high carbohydrate diet on their offspring, in rainbow trout (Oncorhynchus mykiss)
}

\author{
Therese Callet ${ }^{\text {Corresp., } 1}$, Hongyan Li ${ }^{1,2,3}$, Anne Surget ${ }^{1}$, Frederic Terrier ${ }^{1}$, Franck Sandres ${ }^{1}$, Anthony Lanuque ${ }^{1}$, \\ Stephane Panserat ${ }^{1}$, Lucie Marandel ${ }^{\text {Corresp. } 1}$ \\ 1 Institut National de la Recherche pour l'Agriculture, I'Alimentation et l'Environnement (INRAE), Saint-Pée-sur-Nivelle, France \\ 2 State Key Laboratory of Freshwater Ecology and Biotechnology, Instute of Hydrobiology, Chinese Academy of Sciences, Wuhan, China \\ 3 University of Chinese Academy of Sciences, Beijing, China \\ Corresponding Authors: Therese Callet, Lucie Marandel \\ Email address: therese.callet@inrae.fr, lucie.marandel@inrae.fr
}

In order to develop a sustainable salmonid aquaculture, it is essential to continue to reduce the use of the protein-rich fishmeal. One promising solution to do so is the use of plant-derived carbohydrates in diet destined to broodstock. However, in mammals, the reduction of protein content (replaced by carbohydrates) in parental diet is known to have strong adverse effects on offspring phenotypes and metabolism. For the first time, the effect of a paternal and a maternal high carbohydrate-low protein diet was assessed on progeny at long term in the rainbow trout. A 30\% protein diminution in both males and females broodstock diet during 10 month and 5 months, respectively, did not trigger adverse consequences on their offspring. At the molecular level, offspring transcriptomes were not significantly altered, emphasizing no effect on metabolism. Tenuous differences in the biochemical composition of the liver and the viscera were observed. The recorded effects remained in the normal range of value and accordingly offspring growth were not negatively affected over the long term. Overall, we demonstrated here that a $30 \%$ protein diminution during gametogenesis is feasible, confirming the possibility to increase the proportion of plant-derived carbohydrates in female broodstock diets to replace fishmeal proteins. 


\title{
No adverse effect of a maternal high
} carbohydrate diet on their offspring, in Rainbow trout (Oncorhynchus mykiss)

${ }_{4}$ Thérèse Callet ${ }^{1}$, Hongyan $\mathrm{Li}^{1,2,3}$, Anne Surget ${ }^{1}$, Frederic Terrier ${ }^{1}$, Frank ${ }_{5}$ Sandres $^{1}$, Anthony Lanuque ${ }^{1}$, Stéphane Panserat ${ }^{1}$, and Lucie Marandel ${ }^{1}$

6 'INRAE, Université de Pau et des Pays de l'Adour, E2S UPPA, NUMEA, Saint-Pée-sur-Nivelle

2State Key Laboratory of Freshwater Ecology and Biotechnology, Institute of Hydrobiology, Chinese Academy of Sciences, Wuhan, 430072, China ${ }^{3}$ University of Chinese Academy of Sciences, Beijing, 100049, China

Corresponding author:

Thérèse Callet, Lucie Marandel ${ }^{1}$

Email address: therese.callet@inrae.fr, lucie.marandel@inrae.fr

\begin{abstract}
In order to develop a sustainable salmonid aquaculture, it is essential to continue to reduce the use of the protein-rich fishmeal. One promising solution to do so is the use of plant-derived carbohydrates in diet destined to broodstock. However, in mammals, the reduction of protein content (replaced by carbohydrates) in parental diet is known to have strong adverse effects on offspring phenotypes and metabolism. For the first time, the effect of a paternal and a maternal high carbohydrate-low protein diet was assessed on progeny at long term in the rainbow trout. A $30 \%$ protein diminution in both males and females broodstock diet during 10 month and 5 months, respectively, did not trigger adverse consequences on their offspring. At the molecular level, offspring transcriptomes were not significantly altered, emphasizing no effect on metabolism. Tenuous differences in the biochemical composition of the liver and the viscera were observed. The recorded effects remained in the normal range of value and accordingly offspring growth were not negatively affected over the long term. Overall, we demonstrated here that a $30 \%$ protein diminution during gametogenesis is feasible, confirming the possibility to increase the proportion of plant-derived carbohydrates in female broodstock diets to replace fishmeal proteins.
\end{abstract}

\section{INTRODUCTION}

The aquaculture industry is constantly developing better feeds: feeds that are both covering the fish known nutritional requirements and being economical and environmentally friendly. To this end, the research in aquaculture nutrition has notably focused on the replacement of fishmeal and fish oil, traditional ingredients used for rearing aquaculture carnivorous species (Naylor et al., 2009). Plant-derived carbohydrates appear to be good candidates to replace protein included in fishmeal, as they could represent a non-negligible source of energy, help sparing proteins for growth (Hemre et al., 2002) and as they are more available in Europe and cheaper than fishmeal (Prabu et al., 2017). Such substitution will however lead to the decrease of the protein-to-carbohydrate ratio as fishmeal are rich in protein but devoid of carbohydrates (Jobling, 2012).

Even though broodstock have a high protein requirement but no specific requirement for dietary carbohydrates, a study on rainbow trout has recently demonstrated that female trout broodstock are able to grow and reproduce normally over an entire reproductive cycle when fed a diet in which fishmeal have been partially replaced by plant-derived carbohydrates (Callet et al., 2020). Thereby, such ingredients could be a viable solution to replace fishmeal in diets for broodstock.

Nevertheless, it is now recognized that nutritional insults occurred during the peri and prenatal life could affect an individual at long term. As such, both the maternal and the paternal diets could affect their offspring metabolism, phenotypes and health at long term (Rando and Simmons, 2015; Guo et al., 2020), 
in a gender specific manner (Tarrade et al., 2015). This concept is well known as programming or DOHAD (Developmental Origins of Health and Disease) in mammals (Hoffman et al., 2017). In mammals, both the over/under nutritions and an altered macronutrients balance have been studied (Guo et al., 2020). Among the latter, protein restriction and increased carbohydrates proportion in parental diets are known to have deleterious effects on offspring such as the reduction of their lifespan, development of obesity, glucose intolerance and modification of cholesterol metabolism in mammals (Langley-Evans, 2009; Hoffman et al., 2017; Guo et al., 2020). In teleost fish, the concept of programming has also been demonstrated (Hou and Fuiman, 2020). It could therefore be hypothesized that parental high carbohydrates (HC)/low protein (LP) diets could also affect the physiology and the metabolism of their offspring but such question has not been explored so far.

The present study aims to describe the consequences of a parental HC/LP diet in their offspring in carnivorous fish species. To do so, two-year old male and female rainbow trout, which is a commercially important salmonid species, were fed either a control diet (NC, 63.89\% protein and $0 \%$ carbohydrates) or a "high carbohydrate/low protein" diet (HC/LP, $42.96 \%$ protein and $35.30 \%$ carbohydrates) for an entire reproductive cycle for females and for 5 months for males. Crossed-fertilizations were then carried out in order to obtain 4 groups of offspring (Callet et al., 2020). Zootechnical parameters were monitored until offspring reached a market fish size (portion trout). Moreover, transcriptomes of liver and muscle, which are two key tissues in metabolism and are known to be responsive to nutritional programming in trout (Song et al., 2018), were analysed to detect any impact on offspring metabolism.

\section{MATERIALS AND METHODS}

\section{Ethics Approval}

Investigations were conducted according to the guiding principles for the use and care of laboratory animals and in compliance with French and European regulations on animal welfare (Décret 2001-464, 29 May 2001 and Directive 2010/63/EU, respectively). This protocol and the project as a whole were approved by the French National Consultative Ethics Committee (reference numbers 201610061056842).

\section{Experimental design}

Rainbow trout (Oncorhynchus mykiss) produced from broodstock with different nutritional histories were reared during 36 weeks to assess the effects of such nutritional histories.

Broodstock feeding trial was previously described in Callet et al. (2020). Two-year old males and females rainbow trout were fed since the resumption of feeding with either a control diet (NC, 63.89\% protein and $0 \%$ carbohydrates) or a low protein/high carbohydrate (HC/LP, $42.96 \%$ protein and $35.30 \%$ carbohydrates). The experiment has lasted 10 months for females and 5 months for males only as a saprolegnia infection has occurred (see details in Callet et al. (2020)). During the spawning period (November-year 1), spawns from NC and HC/LP females were cross-fertilized with milts from males from each experimental condition in the experimental INRAE facilities of Lees-Athas (Figure 1). Thus, offspring from 4 different conditions were obtained: the control $\mathrm{NN}$ offspring from both males and females fed the NC diet, HN offspring from only females fed the HC/LP diet and males fed the NC diet; NH offspring from only males fed the HC/LP diet and females fed the NC diet; and HH offspring from both parents fed the HC/LP diet. Eggs have hatched in December (year 1), from 44 to 48 days post-fertilization. Yolk-sac fry were then transferred to the INRAE experimental facilities of Donzacq (France). The offspring were reared into 12 tanks ( $\mathrm{n}=3 /$ condition which is the number of tanks needed for nutritional studies (Jobling, 2012)) in a flow-though reared system supplied with natural spring water at $17^{\circ} \mathrm{C}$. For each condition, from 1300 to 1500 fish were randomly assigned to each of the three tanks. Tanks were randomly distributed in the experimental facilities and named without any indication of the offspring's condition. Fish were examined daily and dead fish were removed. Since their first feeding (January-year 2), fish were fed ad libitum with a commercial diet (T3-P Omega, Skretting, France) during 36 weeks (until October-year 2). The initial density was adjusted after 3 weeks (150 fish per tank), 18 weeks (100 fish per tank), 21 weeks ( 70 fish per tank) and finally after 24 weeks (30 fish per tank). Between the 18 and the 21 weeks (mid-June-year 2), due to a technical issues, the water supply has been compromised in one NH tank, triggering a high mortality in this tank. To avoid any effect of the density, the fish from the 3 tanks were mixed and redistributed at equal density in the 3 tanks. Fish were then closely monitored and no consequences were detected after this event. During the growth trial, all fish were treated to prevent flavobacterium infections between 9-12 weeks and between 21-24 weeks (in 
April and June of year 2). Finally, a one day peak in deaths was recorded during the 27-30 weeks period, probably caused by an important stress due to a storm.

\section{Samplings}

Every three weeks, fish were weighted and zootechnical parameters were calculated as follows (by tanks, $\mathrm{n}=3$ tanks):

Survival $(\%)=\left(\mathrm{N}_{\text {final }} / \mathrm{N}_{\text {init }}\right) \times 100$;

Specfic Gowth Rate $(\mathrm{SGR}, \% /$ day $)=100 \times\left(\ln \left(\mathrm{BW}_{\text {final }}\right)-\ln \left(\mathrm{BW}_{\text {init }}\right)\right) /$ day .

Dry feed intake was estimated by removing unconsumed (collected every day) from feed supplied. Feed efficiency (FE) and feed intakes were estimated as follows:

Feed efficiency $(\mathrm{FE})=\left(\mathrm{BW}_{\text {final }}+\mathrm{BW}_{d}-\mathrm{BW}_{\text {init }}\right) /$ dry feed intake

Feed intake $(\mathrm{FI})=100 \times$ dry feed intake $/\left(\left(\mathrm{BW}_{\text {final }}+\mathrm{BW}_{\text {init }}\right) / 2\right) /$ day

Feed intake $\left(\mathrm{FI}_{M B W}\right)=$ dry feed intake $/\left(\left(\mathrm{BW}_{\text {final }} 0.8 \times \mathrm{BW}_{\text {init }}{ }^{0.8}\right)^{0.5} \times\right.$ day $)$

with $\mathrm{N}_{\text {init }}$ and $\mathrm{N}_{\text {final }}$ the initial and final fish number; $\mathrm{BW}_{\text {init }}, \mathrm{BW}_{\text {final }}$ and $\mathrm{BW}_{d}$ the mass for initial, final and dead fish.

After 24 weeks and 36 weeks of feeding (July and October-year 2), fish were sampled. Fish were anesthetized with benzocaine $(30 \mathrm{mg} / \mathrm{L})$ and killed in a benzocaine bath at $60 \mathrm{mg} / \mathrm{L}$. Concerning the 24-weeks-sampling, 9 fish from each condition were randomly sampled and stored at a whole at $-20^{\circ} \mathrm{C}$ for biochemical composition analysis. Concerning the 36-weeks-sampling (October-year 2), 9 individuals by condition were randomly sampled 6 hours after the last feeding. Individual mean body weight (BW) and individual body length (L) were measured and the Fulton's condition factor was calculated as $\mathrm{K}=$ $100 * \mathrm{BW} / \mathrm{L}^{3}(\mathrm{n}=9)$. Blood was removed from the caudal vein and centrifuged at $3000 \mathrm{~g}$ for $5 \mathrm{~min}$. The plasma obtained was stored at $-20^{\circ} \mathrm{C}$ until further analysis. The viscera and hepatopancreas were removed and weighted. The viscerosomatic index (VSI) and hepatosomatic index (HSI) were calculated as HSI(\%) $=100 \times$ liver weight $/$ fish weight and $\operatorname{VSI}(\%)=100 \times$ viscera weight $/$ fish weight $(\mathrm{n}=9)$. The viscera, a part of the liver and a part of muscle were stored at $-20^{\circ} \mathrm{C}$ until biochemical analyses. Another part of the liver and muscle were removed and immediately frozen in liquid and stored at $-80^{\circ} \mathrm{C}$ until RNA extraction. Finally, the caudal fin of each fish were dissected and stored at $-20^{\circ} \mathrm{C}$ until DNA extraction.

\section{Biochemical composition}

Proximate compositions of the feeds, whole-body fish samples (24-weeks-sampling), carcass, liver, muscle, and viscera (36-weeks-sampling) were analysed as follows: dry matter was determined by the oven drying to constant weight at $105^{\circ} \mathrm{C}$; ash was determined via combustion in a muffle furnace at $600^{\circ} \mathrm{C}$ to a constant weight; crude protein $(\mathrm{N} \times 6.25)$ was determined by the Kjeldahl method after acid digestion. Crude lipid in the diets and whole-body were determined by petroleum ether extraction (Soxthern), while total lipid content in the liver and muscle were performed using the dichloromethane/methanol $(2: 1, \mathrm{v} / \mathrm{v})$ as the extraction liquid, according to Folch et al. (1957)

Hepatic glycogen and glucose content were performed in lyophilized liver. Glycogen content was determined following to the hydrolysis methods described by Good et al. (1933). Samples were ground in $\mathrm{HCl}(1 \mathrm{~mol} / \mathrm{L})$ and aliquot were made for two separate parts. For the free glucose measurement, one of the aliquot samples were detected using the Amplite Fluorimetric Glucose Quantitation Kit (AAT Bioquest, Inc., USA) after centrifuged at $10000 \mathrm{~g}$ for $10 \mathrm{~min}$. For the glycogen measurement, the other part of the ground tissue was boiled at $100^{\circ} \mathrm{C}$ for $2.5 \mathrm{~h}$, adjusted to neutralization by $\mathrm{KOH}(5 \mathrm{~mol} / \mathrm{L}$, VWR, USA), and determined using the same kits as above according to the manufacturer's instructions. Finally, glycogen content was evaluated by subtracting free glucose content. Between 24 and 36 weeks, protein and lipid retentions (PRE and LRE) were also estimated as follows ( $\mathrm{n}=3)$ : PRE, $\mathrm{LRE}=\left(\mathrm{BW}_{\text {final }} \times \mathrm{X}_{\text {final }}-\mathrm{BW}_{\text {initl }} \times \mathrm{X}_{\text {init }}\right) / \mathrm{NI}_{x}$ with $\mathrm{X}_{\text {init }}$ and $\mathrm{X}_{\text {final }}$ the initial and final carcass content in protein/lipids (in $\mathrm{g}$ ) and $\mathrm{NI}_{x}$ the protein/lipids intake (in $\mathrm{g}$ DM).

\section{Plasma metabolites}

Plasma glucose, triglycerides, free fatty acids (FFA) and cholesterol concentrations were analysed with 4 kits (Glucose RTU, PAP 150 bioMerieux, Marcy l'Etoile, France, Fujifilm Wako, Sobioda and CHOD-PAP, Sobioda), according to the recommendations of manufacturer $(n=9)$. 


\section{DNA extraction and determination of fry sex}

DNA was extracted from the caudal fin of fish sampled after 36 weeks of feeding, using Chelex-100 (Bio-Rad Laboratories, CA, USA), following manufacturer's instructions $(n=9)$. To assess offspring sex, the master sex-determining gene, $s d Y$ genes, was amplified by PCR from the extracted, as described in Yano et al., (Yano et al., 2013). One $\mu 1$ of DNA were mixed with $1.25 \mu \mathrm{l}$ of each primer (10mM, forward: CCCAGCACTGTTTTCTTGTCTCA; reverse: CTGTTGAAGAGCATCACAGGGTC), $1 \mu 1$ dNTP mixture and $5 \mu 1$ of $5 \times$ PCR Buffer (Promega) with $0.125 \mu 1$ of Taq DNA Polymerase (Promega) in a total volume of $25 \mu \mathrm{L}$. Thermal cycling consisted of denaturation for $20 \mathrm{sec}$ at $94^{\circ} \mathrm{C}$ followed by 35 cycles of $94^{\circ} \mathrm{C}$ for $20 \mathrm{~s}, 59^{\circ} \mathrm{C}$ for $20 \mathrm{~s}$, and $72^{\circ} \mathrm{C}$ for $20 \mathrm{~s}$, with a final extension of $5 \mathrm{~min}$ at $72^{\circ} \mathrm{C}$. PCR products were electrophoresed on a $2 \%$ agarose gel to reveal the presence or absence of sdY.

\section{RNA extraction}

Liver and white muscle samples after 36 weeks were homogenised in Trizol reagent (Invitrogen, Carlsbad, CA, USA) using the Precellys 24 (Bertin Technologies, Montigny-le-Bretonneux, France). The total RNA was then extracted according to the Trizol manufacturer's instructions $(n=9)$. The concentration of extracted RNA was analysed using a spectrophotometer (Nanodrop ND1000, LabTech) by measuring absorbance at $260 \mathrm{~nm}$ and quality of RNAs was checked with Bioanalyzer (Agilent Technologies, Kista, Sweden).

\section{Microarrays, cDNA labelling and hybridisation}

Transciptome profiles of liver and muscles were analysed with microarray technology (Agilent-based microarray platform rainbow trout specific with $8 \times 60 \mathrm{~K}$ probes), as previously described (Callet et al., 2018). Briefly, six RNA samples were selected among the 9 per condition, thanks to their RIN number. RNA was amplified by a reverse transcription, using a polyDT T7 primer (denaturation step: $10 \mathrm{~min}$ at $65^{\circ} \mathrm{C}$, reaction step: 2 hour at $40^{\circ} \mathrm{C}$, inactivation step: $5 \mathrm{~min}$ at $70^{\circ} \mathrm{C}$ ) and the obtained cRNA were labelled with Cy3-dye $\left(2 \mathrm{hr}\right.$ at $\left.40^{\circ} \mathrm{C}\right)$. A RNeasy kit (Qiagen) was used to remove excess dye. The level of dye incorporation was evaluated using a spectrophotometer (Nanodrop ND1000, LabTech) (Yield $\geq$ $0.825 \mu \mathrm{g}$ cRNA and specific activity $\geq 6$ pmol of Cy3 per $\mu \mathrm{g}$ of cRNA). $600 \mathrm{ng}$ of Cy3-cRNA was then fragmented with a specific buffer $\left(30\right.$ minutes at $\left.60^{\circ} \mathrm{C}\right)$. Cy3-cRNA were then manually hybridised on a sub-array $\left(17 \mathrm{~h}\right.$ at $65^{\circ} \mathrm{C}$ in a microarray hybridisation oven). After washing, slides were scanned (Agilent DNA Microarray Scanner, Agilent Technologies, Massy, France, parameters: $3 \mu \mathrm{m}$ and 20 bits). Data were then obtained with the Agilent Feature Extraction software (10.7.1.1) and are available in the GEO database (ID: GSE169003).

\section{Statistical analyses}

All data were presented as means \pm standard deviation and the statistical analyses were performed using the R Software (version 3.2.5) (R Core Team, 2013). The significance threshold p-value was set at 0.05 . Zootechnical parameters (mean body weight, survival, SGR, FI, FE, LRE and PRE) obtained throughout the trial were analysed using a Kruskal-Wallis test to assess the effect of the parental HC/LP diet. In case of a significant effect of the parental HC/LP diet, a Bartlett post-hoc test was carried out in order to decipher which condition was significantly different from the control NN fish.

Data obtained from the last sampling after 36 weeks of feeding were analysed thanks to linear mixedeffects models, using the packages "lme4" from the R software. The maternal HC/LP diet, the paternal HC/LP diet and the interaction between these two variables were investigated on all the parameters measured. As a sexual dimorphism in programming have been described in mammals (Tarrade et al., 2015), the effect of sex of the fish and the interaction between the sex and the parental HC/LP were thus also investigated on all the parameters. The tank was treated as a random effect. The best model based was then chosen thanks to the Akaike Information Criterion (AIC). Diagnostics plots were created for each model to evaluate the model assumptions. In case of a significant interaction, a Tukey post-hoc test was carried out.

Data from the microarray analysis were transformed with a logarithmic transformation, scale normalised and analysed using the package Limma (Ritchie et al., 2015). In order to find the differentially expressed genes resulting from the maternal, paternal and both maternal and paternal HC/LP diet, transcriptomes of $\mathrm{HN}, \mathrm{NH}$ and $\mathrm{HH}$ liver and muscles were successively compared with the transcriptomes of the control $\mathrm{NN}$ fish. For these three comparisons, Limma t-tests were performed, with a correction for multiple 
tests (P-value cut-off $=0.05$ after a Benjamini-Hochberg correction), taking into account the sex of the fish.

\section{RESULTS}

\section{Zootechnical parameters during the growth trial}

During the trial, zootechnical parameters were monitored (Supplemental file 1) and were affected differently depending on the period (Table 1). During the 3 weeks after the first feeding, while $\mathrm{HN}$ offspring have displayed a significantly lower growth and a lower final body weights, the $\mathrm{NH}$ and $\mathrm{HH}$ offspring have displayed a significantly higher growth and higher final body weights. Between 18 and 21, a high mortality occurred in one NH tank due to a technical issue (see Material and methods). This issue and the associated mortality triggered a diminution of feed intake in this same tank. Except from this period with the technical issue (18-21 weeks), NH and HH offspring had a higher FI but a lower FE during the growth trial. Their growth and final body weights were however never affected, except after 24 weeks when $\mathrm{NH}$ offspring have exhibited a higher mean body weights than the NN control one. Finally, HN and $\mathrm{HH}$ offspring have exhibited a slightly higher survival rates than the $\mathrm{NN}$ control fish during the one day peak mortality which occurred during the storm (see Material and methods).

\section{Zootechnical parameters at the end of the growth trial}

The individual body weight was not significantly different among the conditions (Figure 2 and supplemental file 2 for the detailed statistical results). $\mathrm{NH}$ and $\mathrm{HH}$ offspring were significantly shorter than $\mathrm{HN}$ and $\mathrm{NN}$ ones regardless of their sex $(-5.0 \%$, P-value $=0.02)$. For $\mathrm{HN}$ and $\mathrm{HH}$ offspring, the Fulton's condition factor was significantly increased in comparison to $\mathrm{NH}$ and $\mathrm{NN}$ ones, regardless of their sex $(+6.5 \%$, P-value $=0.04)$.

\section{Metabolic parameters at the end of the growth trial}

After 9 months of feeding, plasmatic parameters were measured (Figure 3 and supplemental file 2 for the detailed statistical results). Offspring plasma glucose concentrations were significantly decreased in $\mathrm{HN}$ and $\mathrm{HH}$ offspring in comparison to $\mathrm{NN}$ and $\mathrm{NH}$ ones $(-12.1 \%$, P-value $=0.04)$. Females offspring had a significantly lower cholesterolemia than males ones $(-13.3 \%$, P-value $=0.009)$ and $\mathrm{HH}$ and $\mathrm{HN}$ offspring tended to have a higher cholesterolemia than the $\mathrm{NH}$ and $\mathrm{NN}$ ones regardless of their sex $(+17.5 \%, \mathrm{P}$-value $=0.06)$. Females offspring had also a significantly lower FFA plasmatic level than males ones (P-value $=0.002)$ and the $\mathrm{HN}$ offspring had a $36.0 \%$ lower FFA plasmatic level than the control NN fish, regardless of their sex $(\mathrm{P}$-value $=0.007)$. Finally, while no differences were detected in plasma triglycerides concentrations of females offspring, males $\mathrm{HH}$ had a significantly higher plasmatic triglycerides concentrations than $\mathrm{NN}$ ones $(\mathrm{P}$-value $=0.02)$.

Biochemical compositions of livers, viscus and muscles were analysed (Figure 4 and supplemental file 2 for the detailed statistical results). No differences on HSI were detected among conditions. $\mathrm{NH}$ and $\mathrm{HH}$ offspring had a $8.6 \%$ higher protein content than the $\mathrm{NN}$ and $\mathrm{HN}$ ones (P-value $=0.04$ ). While, females $\mathrm{HN}$ an $\mathrm{HH}$ had a lower hepatic lipid content than $\mathrm{NN}$ ones, males HH offspring had a higher lipid content than NN ones (P-value $=0.003$ ). Also, $\mathrm{NH}$ and $\mathrm{HH}$ offspring had a $36.0 \%$ lower glycogen content than the $\mathrm{NN}$ and $\mathrm{HN}$ fish (P-value $=0.02$ ). Finally, $\mathrm{HN}$ and $\mathrm{HH}$ offspring had a $19.6 \%$ lower glucose content that $\mathrm{NH}$ and $\mathrm{NN}$ fish (P-value $=0.02$ ).

While no differences on VSI were detected among females offspring, males HH offspring had a lower VSI than $\mathrm{NN}$ ones $(\mathrm{P}$-value $=0.06)$. No significant differences were detected in the viscus protein content among offspring. Females $\mathrm{NH}$ and $\mathrm{HH}$ had a higher viscus lipid content than $\mathrm{NN}$ and $\mathrm{HN}$ ones (P-value $=0.003$ ). No significant differences were detected in the muscle protein content among offspring. Muscle lipid content did not differ among females offspring, but males $\mathrm{NH}$ offspring had a significant lower lipid content than $\mathrm{HN}$ ones.

\section{Muscle and hepatic transcriptomes at the end of the growth trial}

In muscle, 3 probes were found differentially expressed between $\mathrm{HN}$ and $\mathrm{NN}$ and 29 between $\mathrm{HH}$ and NN, irrespective of their sex (Table 2). Regardless of their sex, 18 probes were found differentially expressed between $\mathrm{HH}$ and $\mathrm{NN}$ offspring in liver (Table 3). No probes were found differentially expressed between $\mathrm{NH}$ and $\mathrm{NN}$ nor in liver, nor in muscle. 


\section{DISCUSSION}

Plant-derived carbohydrates appear to be a possible solution to replace fishmeal proteins in broodstock diets with higher trophic levels to progress toward a sustainable aquaculture (Callet et al., 2020). As it has been demonstrated in numerous studies that both the maternal and the maternal nutrition could affect their offspring in different fish species (Hou and Fuiman, 2020), consequences of a parental HC/LP diet need to be assessed and more particularly when they reach a market fish size.

\section{The paternal history had only slightly affected their offspring tissue composition}

It is increasingly acknowledged that paternal diets, such as paternal HC/LP diets, could affect their offspring phenotypes and health at long term (Rando, 2012; Watkins et al., 2020). In the present study, due to a Saprolegnia infection which occurred during gametogenesis, the surviving males used for the reproduction could have been selected (Callet et al., 2020). The effect of the paternal HC/LP diet is thus combined with the effect of a potential selection. It is therefore impossible to decipher if the changes observed are due to the selection of males or due to the HC/LP diet received during the first period of gametogenesis, and we will refer such effects as paternal history effects.

The paternal history (HC/LP diet and selection) positively affect fish body weight at the beginning of the trial. However, such positive effect seems to fade along time as fish growth were not affected anymore beyond 3 weeks and fish length was slightly reduced at the end of the trial. Such outcome are probably resulting from the balance between a higher feed intake and a lower feed efficiency, reflected by a tendency to have a lower protein retention (Refer to Table 1).

Beside, at the end of the trial, the increase in hepatic glycogen content, which remained within known values for salmonids (Vijayan and Moon, 1992), was probably linked to the protein content decrease. Such phenotypes alterations are similar of what have been observed in offspring derived from males fed HC/LP diets in other species. For instance, it has been also shown that a HC/LP diet have modulated protein and glycogen content in drosophila melanogaster (Matzkin et al., 2011, 2013). Moreover, adiposity was increased in viscera of female offspring. Interestingly, even though these changes were limited (Kolditz et al., 2008), they are in agreement with results obtained in mice in which paternal HC/LP diets have also triggered an increase in body adiposity (Watkins et al., 2018). In mammalian models, such effects on phenotypes could arise from a perturbation of hepatic metabolism, which gene expression are symptomatic of non-alcoholic fatty liver disease (Watkins et al., 2018).

In spite of these differences observed in tissues composition, no specific metabolic pathway seemed to be affected by the paternal history as no genes were found differentially expressed in NH fish and only 18 were found in $\mathrm{HH}$, regardless of their sex. Moreover, those 18 genes were not directly linked to intermediary metabolism. Because of a saprolegnia injury, the male broodstock were fed only during 5 months and were then re-fed with the control NC diet until reproduction (Callet et al., 2020). In addition to the severity of the nutritional insults, the window when is applied the insult has an importance for the imprinting of the nutritional programming. However, in fish, this critical window has not been clearly defined and the dietary shift could explain the small changes observed in $\mathrm{NH}$ and $\mathrm{HH}$ fish phenotypes and accordingly the unaffected transcriptomes.

\section{Offspring condition factor had been improved by the maternal HC/LP diet}

It is well recognized that maternal low protein diets could affect their offspring phenotypes, metabolism and health at long term. More particularly, numerous studies have also showed that glucose homeostasis could also be affected in offspring derived from parents fed a HC/LP diet (Langley et al., 1994; Desai et al., 1995; Ozanne and Hales, 2002). Regarding this, in the present study, the maternal HC/LP diet have slightly affected plasmatic glucose concentrations and the hepatic free glucose content in offspring. These changes were however only subtle (-12.1\% for the plasmatic concentrations and $-19.6 \%$ the hepatic free glucose content) and remained in the normal range of value found in salmonids (Congleton and Wagner, 2006). Moreover, no changes were detected at a molecular level as no genes were found differentially expressed in the liver of $\mathrm{HN}$ offspring and only 18 were found in $\mathrm{HH}$ ones, regardless of their sex. The only gene related to glucose metabolism differentially expressed between $\mathrm{HH}$ and $\mathrm{NN}$ fish was the gene coding for the Glut6 transporter (solute carrier family 2 member 6 ), which was down-regulated in the muscle of $\mathrm{HH}$ fish in comparison to the control NN fish. While maternal HC/LP diets are known to affect Glut4 expression in skeletal muscle (Zheng et al., 2012), the role of Glut6, transporter belonging to the class III glucose transporters, has not been investigated yet. Together, these results suggested that the 
HC/LP diet did not altered their offspring metabolism.

Also, except from a reduction of their offspring body weights during the 3 first weeks of the trial, the maternal HC/LP diet did not compromise their offspring phenotypes. This negative effect of nutritional programming was then lost when fish grew in physiological condition and are not subjected to stressful situations. Such fading events along time has also been previously described in sea bass (ZamboninoInfante et al., 2019). At long term, the parental diet even improved their offspring Fulton's condition factor, which mirrors fish health (Kroon et al., 2017). This augmentation could be of particular interest for the aquaculture sector. Such results in rainbow trout highly differed from other studies in mammals in which the maternal protein restriction during pregnancies could highly prejudice offspring health at long term, inducing obesity (Ozanne and Hales, 2002; Zohdi et al., 2015). Even though it has been reported that the effects of programming are strikingly constant across species (Langley-Evans, 2009), the differences reported here could be explained by two main reasons. First, because they have different developmental processes, mechanisms behind the programming events may highly differ in mammals and fish species, leading thus to different consequences. Second, the reduction of protein content in the HC/LP diet have reached 30\% but still met the known nutritional requirement for rainbow trout broodstock (Jobling, 2012).

\section{Existence of a synergistic effect of the paternal and maternal HC/LP diet}

Interestingly, the $\mathrm{HH}$ offspring have exhibited extreme value in comparison to the control NN fish for several of the recorded phenotypical traits. First, HH offspring had the highest $\mathrm{K}$ index, suggesting an improved health. However, their metabolism seemed to have been affected as they have also displayed the highest cholesterolemia and the highest plasmatic triglycerides levels (HH males only). HH offspring had also the most altered hepatic biochemical composition (highest protein content combined with the lowest glycogen and glucose content). HH males had also the highest lipid hepatic content in comparison to NN ones. Finally, males HH offspring had the lowest VSI. Such phenotype differences were logically associated with molecular data. Even if the number of genes differentially expressed between these two conditions remained low, $\mathrm{HH}$ offspring have the most reshaped hepatic and muscle transcriptomes in comparison to the control $\mathrm{NN}$ ones.

Therefore, the effects triggered by the paternal and by the maternal HC/LP diet seem to have cumulated. Such synergistic effect of parental nutrition have not been deeply investigated so far. Previous studies in mammals have however demonstrated that the negative effects induced by maternal and paternal condition (obesity) or nutrition (high sugar diet) could accumulate in their offspring (McPherson et al., 2015; Finger et al., 2015; Ornellas et al., 2016, 2019). A better understanding of the mechanisms behind the imprinting of programming events due to the maternal and the paternal is needed to better apprehend their possible interactions.

In addition to the interaction between the paternal and the maternal nutrition, the design of studies on programming in fish should also take into account the sex of the progeny. Although this was not the major purpose of our study, we have shown that males HH offspring appeared to be more sensitive to programming than females ones, confirming results obtained in mammals (Tarrade et al., 2015). As fish were raised together in tanks, without distinguishing sex, such effect have only been tested at the final sampling point (36 weeks) and it is thus not possible to decipher if the offspring's sex have affected other zootechnical parameters of interest for aquaculture, such as feed intake or feed efficiency. These preliminary results however indicate that fish gender might modulate the effect of programming via a parental HC/LP diet.

\section{CONCLUSION}

Despite the important reduction of the protein content in the diet of broodstock during gametogenesis (from $63.89 \%$ to $42.96 \%$ ), no adverse effects of the parental history were recorded in offspring growth at long term. These results are highly contrasting with results obtained in mammals where the diminution of protein content in parental diet has strong negative effect on their offspring. Differences observed in tissues composition were negligible and remained in the normal range of value, which is confirmed by the molecular data. Of particular interest, the maternal HC/LP diet had even slightly increased fish condition factor, suggesting an improvement of fish health. Further studies should be carried out to validate this positive result. All together, this first study on the the long-term effect of a parental HC/LP diet in teleost fish confirms that HC/LP diets are suitable for such carnivorous species, supporting thus the feasibility to 
increase the proportion of plant-derived carbohydrates in broodstock diets to replace fishmeal proteins.

\section{Figures and Tables}

Table 1: Zootechnical parameters during the trial

Data are presented as mean \pm standard deviation and analyzed by a kruskal-wallis test. In case of significant effect of the parental history, results are presented in bold $(P$-values $\leq 0.05)$ and a post-hoc Dunnet test was performed. Significant differences in comparison to the control NN group are represented with stars (P-value $\leq 0.001^{\prime * * * ',}, \mathrm{P}$-value $\leq \$ 0.01^{\prime * * '}$, P-value $\left.\leq 0.05^{\prime * \prime}\right)$.

\begin{tabular}{|c|c|c|c|c|c|}
\hline \multirow{2}{*}{ Index } & \multicolumn{4}{|c|}{ Parental history } & \multirow{2}{*}{$\begin{array}{l}\text { Statistical } \\
\text { analyses }\end{array}$} \\
\hline & NN & NH & $\mathrm{HN}$ & $\mathbf{H H}$ & \\
\hline \multicolumn{6}{|l|}{$0-3$ weeks } \\
\hline Initial BW (g) & $0.08 \pm 0.00$ & $0.08 \pm 0.00$ & $0.08 \pm 0.00$ & $0.08 \pm 0.00$ & $n s$ \\
\hline Final BW (g) & $0.25 \pm 0.00$ & $0.27 \pm 0.00^{\star \star \star}$ & $0.24 \pm 0.00^{\star \star \star}$ & $0.27 \pm 0.00^{\star \star \star}$ & 0.02 \\
\hline Survival (\%) & $100.0 \pm 0.00$ & $100.0 \pm 0.00$ & $100.0 \pm 0.00$ & $100.0 \pm 0.00$ & ns \\
\hline SGR (\%/day) & $6.60 \pm 0.00$ & $6.95 \pm 0.00^{\star \star \star}$ & $6.40 \pm 0.00^{\star \star \star}$ & $6.97 \pm 0.00^{\star \star \star}$ & 0.01 \\
\hline Feed intake $(\mathrm{g} \mathrm{DM} / \mathrm{g} / \mathrm{d})$ & $1.42 \pm 0.16$ & $1.33 \pm 0.18$ & $1.43 \pm 0.14$ & $1.22 \pm 0.19$ & $n s$ \\
\hline Feed intake $\left(\mathrm{g} \mathrm{DM} / \mathrm{g}^{0.8 / \mathrm{d}}\right)$ & $4.76 \pm 0.51$ & $4.61 \pm 0.62$ & $4.81 \pm 0.46$ & $4.22 \pm 0.61$ & $n s$ \\
\hline Feed efficency & $4.26 \pm 0.48$ & $4.74 \pm 0.65$ & $4.11 \pm 0.39$ & $5.22 \pm 0.81$ & $n s$ \\
\hline \multicolumn{6}{|l|}{ 3-18 weeks } \\
\hline Final BW $(\mathrm{g})$ & $24.87 \pm 0.13$ & $25.86 \pm 2.40$ & $24.39 \pm 1.02$ & $23.92 \pm 1.02$ & ns \\
\hline Survival (\%) & $96.67 \pm 1.15$ & $84.67 \pm 19.63$ & $98.44 \pm 0.38$ & $96.89 \pm 1.54$ & $n s$ \\
\hline SGR (\%/day) & $4.36 \pm 0.00$ & $4.34 \pm 0.09$ & $4.37 \pm 0.04$ & $4.26 \pm 0.04$ & ns \\
\hline Feed intake (g DM/g/d) & $1.43 \pm 0.01$ & $1.50 \pm 0.06$ & $1.42 \pm 0.01$ & $1.47 \pm 0.02$ & 0.03 \\
\hline Feed intake $\left(\mathrm{g} \mathrm{DM} / \mathrm{g}^{0.8} / \mathrm{d}\right)$ & $22.87 \pm 0.07$ & $21.88 \pm 1.26$ & $22.98 \pm 0.44$ & $22.53 \pm 0.09$ & ns \\
\hline Feed efficency & $1.31 \pm 0.01$ & $1.27 \pm 0.02^{\star}$ & $1.32 \pm 0.01$ & $1.27 \pm 0.02^{*}$ & 0.03 \\
\hline \multicolumn{6}{|l|}{ 18-21 weeks } \\
\hline Final BW $(\mathrm{g})$ & $46.06 \pm 1.29$ & $51.29 \pm 3.02$ & $45.40 \pm 2.27$ & $45.27 \pm 0.61$ & 0.08 \\
\hline Survival (\%) & $100.00 \pm 0.00$ & $68.91 \pm 1.13^{\star \star}$ & $100.00 \pm 0.00$ & $100.00 \pm 0.00$ & 0.01 \\
\hline SGR (\%/day) & $3.23 \pm 0.10$ & $3.39 \pm 0.13$ & $3.23 \pm 0.07$ & $3.17 \pm 0.02$ & $n s$ \\
\hline Feed intake $(\mathrm{g} \mathrm{DM} / \mathrm{g} / \mathrm{d})$ & $2.96 \pm 0.07$ & $2.91 \pm 0.10$ & $2.91 \pm 0.10$ & $3.09 \pm 0.05$ & ns \\
\hline Feed intake $\left(\mathrm{g} \mathrm{DM} / \mathrm{g}^{0.8} / \mathrm{d}\right)$ & $15.80 \pm 0.42$ & $14.55 \pm 0.58^{\star}$ & $15.45 \pm 0.67$ & $16.40 \pm 0.29$ & 0.04 \\
\hline Feed efficency & $1.05 \pm 0.03$ & $1.09 \pm 1.03$ & $1.08 \pm 0.02$ & $0.99 \pm 0.01$ & $n s$ \\
\hline \multicolumn{6}{|l|}{ 21-24 weeks } \\
\hline Final BW (g) & $80.57 \pm 2.06$ & $89.40 \pm 2.67^{\star \star}$ & $83.44 \pm 2.47$ & $82.95 \pm 1.62$ & 0.05 \\
\hline Survival (\%) & $100.00 \pm 0.00$ & $100.00 \pm 0.00$ & $99.52 \pm 0.82$ & $100.00 \pm 0.00$ & ns \\
\hline SGR (\%/day) & $2.31 \pm 0.08$ & $2.32 \pm 0.12$ & $2.53 \pm 0.13$ & $2.46 \pm 0.02$ & 0.09 \\
\hline Feed intake (g DM/g/d) & $2.53 \pm 0.24$ & $2.69 \pm 0.02$ & $2.64 \pm 0.03$ & $2.76 \pm 0.03$ & 0.05 \\
\hline Feed intake $\left(\mathrm{g} \mathrm{DM} / \mathrm{g}^{0.8} / \mathrm{d}\right)$ & $14.02 \pm 0.37$ & $15.09 \pm 0.23$ & $14.73 \pm 0.26$ & $15.40 \pm 0.16$ & 0.07 \\
\hline Feed efficency & $0.89 \pm 0.07$ & $0.84 \pm 0.04$ & $0.93 \pm 0.04$ & $0.86 \pm 0.01$ & ns \\
\hline \multicolumn{6}{|l|}{ 24-36 weeks } \\
\hline Survival (\%) & $86.67 \pm 5.77$ & $92.22 \pm 3.85$ & $98.89 \pm 1.92^{\star \star}$ & $97.78 \pm 1.92^{\star}$ & 0.04 \\
\hline SGR (\%/day) & $1.51 \pm 0.03$ & $1.39 \pm 0.08$ & $1.47 \pm 0.01$ & $1.45 \pm 0.08$ & ns \\
\hline Feed intake (g DM/g/d) & $1.42 \pm 0.11$ & $1.53 \pm 0.04$ & $1.36 \pm 0.06$ & $1.50 \pm 0.03$ & 0.07 \\
\hline Feed intake $\left(\mathrm{g} \mathrm{DM} / \mathrm{g}^{0.8} / \mathrm{d}\right)$ & $9.21 \pm 0.57$ & $9.90 \pm 0.12$ & $9.16 \pm 0.31$ & $10.01 \pm 0.07^{\star \star}$ & 0.03 \\
\hline Feed efficency & $0.98 \pm 0.09$ & $0.82 \pm 0.04^{\star}$ & $0.95 \pm 0.04$ & $0.86 \pm 0.05$ & 0.05 \\
\hline Protein retention (\%) & $28.24 \pm 7.98$ & $24.02 \pm 3.24$ & $29.73 \pm 5.39$ & $26.40 \pm 2.43$ & 0.06 \\
\hline Lipid retention (\%) & $64.78 \pm 7.98$ & $62.40 \pm 3.24$ & $73.98 \pm 5.39$ & $69.42 \pm 2.43$ & $n s$ \\
\hline
\end{tabular}


Table 2: Transcriptomic analyses in muscle

Probes differentially expressed between $\mathrm{HN}$ and $\mathrm{NN} ; \mathrm{HH}$ and $\mathrm{NN}$ in muscle, after limma t-tests (Adjusted $\mathrm{P}$-Value $\leq 0.05$, Benjamini-Hotchberg)

\begin{tabular}{|c|c|c|}
\hline Description & LogFC & $\begin{array}{l}\text { Adjusted } \\
\text { P-Value }\end{array}$ \\
\hline \multicolumn{3}{|l|}{ HN vs NN } \\
\hline E3 ubiquitin-protein ligase HECTD2 & -0.87 & $1.74 \mathrm{E}-02$ \\
\hline Probable E3 ubiquitin-protein ligase HERC5 & -1.27 & $1.92 \mathrm{E}-02$ \\
\hline microtubule-associated protein 6 homolog & -0.73 & 3.39E-02 \\
\hline \multicolumn{3}{|l|}{$H H$ vs NN } \\
\hline Transposable element Tcb1 transposase putative mRNA & -1.37 & 3.35E-05 \\
\hline solute carrier family 2 member 6 & -0.92 & 1.96E-02 \\
\hline No description & 2.47 & 1.96E-02 \\
\hline $60 S$ ribosomal protein L22 putative mRNA & -1.13 & 2.03E-02 \\
\hline No description & 1.06 & 2.03E-02 \\
\hline No description & -1.48 & 2.49E-02 \\
\hline dynamin-1-like protein & -0.84 & 2.49E-02 \\
\hline transcription factor PU.1-like & -0.82 & 2.49E-02 \\
\hline probable E3 ubiquitin-protein ligase HECTD2 & -0.74 & 2.49E-02 \\
\hline ATP-sensitive inward rectifier potassium channel 11-like & -0.85 & 2.57E-02 \\
\hline MHC class I antigen (Onmy-U41p) pseudogene & -1.20 & 2.90E-02 \\
\hline No description & -0.99 & 2.90E-02 \\
\hline pyruvate dehydrogenase (lipoamide) beta & 0.71 & $2.90 \mathrm{E}-02$ \\
\hline No description & 2.24 & 3.35E-02 \\
\hline Poly(ADP-ribose) polymerase 1 & -0.67 & $3.40 \mathrm{E}-02$ \\
\hline No description & 0.60 & $3.40 \mathrm{E}-02$ \\
\hline inward rectifier potassium channel 16-like & 0.75 & $3.40 \mathrm{E}-02$ \\
\hline ATP-sensitive inward rectifier potassium channel 10-like & -1.08 & $3.62 \mathrm{E}-02$ \\
\hline myoferlin-like & 0.55 & $3.74 \mathrm{E}-02$ \\
\hline No description & -1.23 & $3.88 \mathrm{E}-02$ \\
\hline Heterogeneous nuclear ribonucleoprotein $\mathrm{A} 0$ & -1.03 & $3.88 \mathrm{E}-02$ \\
\hline dehydrodolichyl diphosphate synthase & -0.92 & $3.88 \mathrm{E}-02$ \\
\hline non-syndromic hearing impairment protein 5 -like & -0.88 & 3.88E-02 \\
\hline Spi-1/PU.1 transcription factor & -0.72 & 3.88E-02 \\
\hline Transmembrane protein 136 & -0.71 & $3.88 \mathrm{E}-02$ \\
\hline exosome component 4 & -0.68 & $3.88 \mathrm{E}-02$ \\
\hline No description & -0.47 & $3.88 \mathrm{E}-02$ \\
\hline No description & 0.67 & 4.64E-02 \\
\hline unconventional myosin-X-like & 1.53 & $5.00 \mathrm{E}-02$ \\
\hline
\end{tabular}


Table 3: Transcriptomic analyses in liver

Probes differentially expressed between $\mathrm{HH}$ and $\mathrm{NN}$ in liver, after a limma t-tests (Adjusted PValue $\leq 0.05$, Benjamini-Hotchberg)

\begin{tabular}{lll}
\hline Descriptions & LogFC & $\begin{array}{l}\text { Adjusted } \\
\text { P-Value }\end{array}$ \\
\hline HH $\boldsymbol{v s}$ NN & & \\
proton-coupled folate transporter-like & 1.36 & $3.55 \mathrm{E}-02$ \\
nebulin-like & 1.12 & $3.55 \mathrm{E}-02$ \\
protein enabled homolog & 0.90 & $3.55 \mathrm{E}-02$ \\
acidic fibroblast growth factor intracellular-binding & 0.88 & $3.55 \mathrm{E}-02$ \\
protein B-like & & $4.14 \mathrm{E}-02$ \\
No description & 1.89 & $4.14 \mathrm{E}-02$ \\
No description & 1.82 & $4.14 \mathrm{E}-02$ \\
afadin-like & 1.37 & $4.14 \mathrm{E}-02$ \\
protein FAM219B-like & 1.18 & $4.14 \mathrm{E}-02$ \\
single-stranded DNA-binding protein 3 & 1.01 & $4.14 \mathrm{E}-02$ \\
kinesin-associated protein 3-like & 0.83 & $4.14 \mathrm{E}-02$ \\
No description & -0.80 & $4.14 \mathrm{E}-02$ \\
major histocompatibility complex class I-related & -2.01 & $4.14 \mathrm{E}-02$ \\
gene protein-like & -2.06 & $4.18 \mathrm{E}-02$ \\
cytochrome P450 2B4-like & 0.86 & $4.71 \mathrm{E}-02$ \\
neuromedin-U-like & 1.70 & $4.73 \mathrm{E}-02$ \\
cationic amino acid transporter 4-like & -0.63 & \\
lysine-specific demethylase 5C-like & & \\
\hline
\end{tabular}




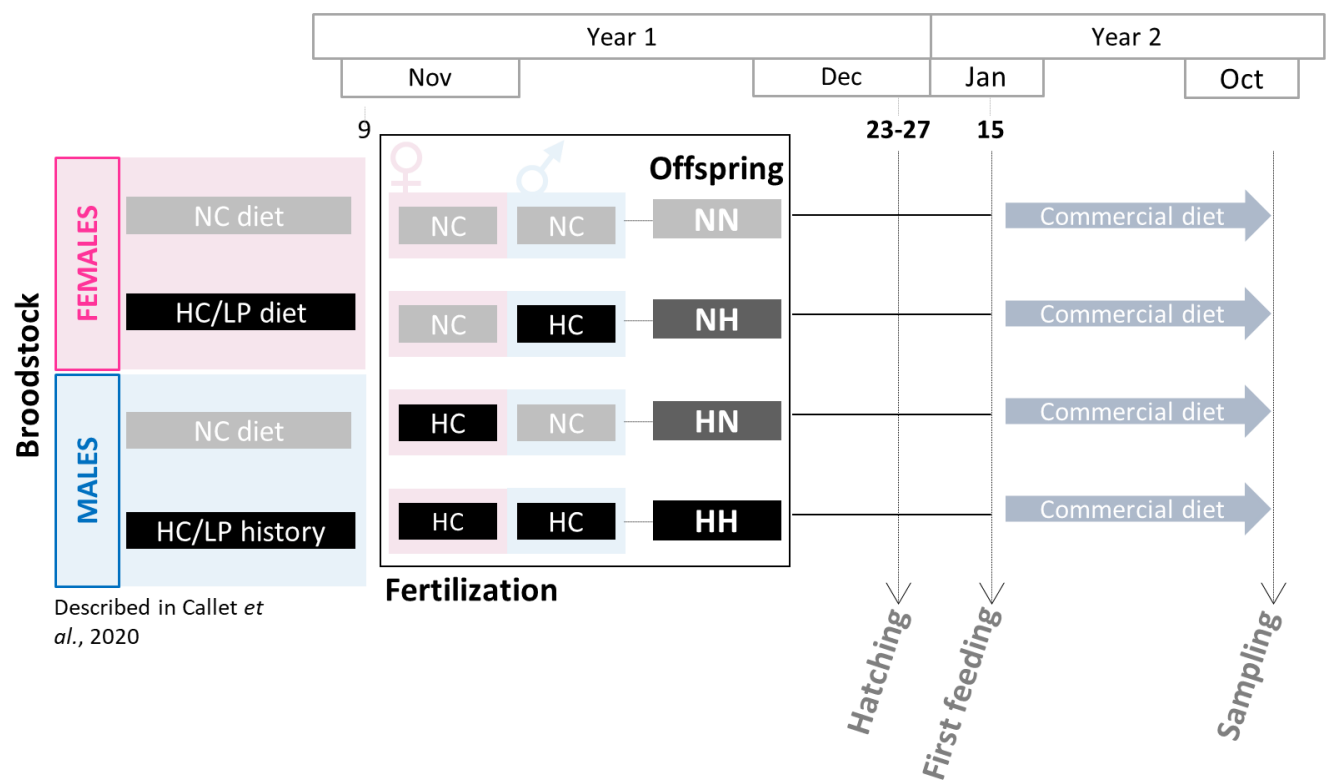

Figure 1. Experimental design. Broodstock females and males have been fed with either the NC diet (no-carbohydrates) or the HC/LP (high carbohydrates/low protein) diet. Cross-fertilizations were carried over to obtained four groups of offspring: $\mathrm{NN}, \mathrm{NH}, \mathrm{HN}$ and $\mathrm{HH}$. Offspring were then fed during one year with a commercial diet to assess the effect of the parental HC/LP diet.

Supplemental file 1: Zootechnical parameters monitored during the entire trial. Raw data monitored during the entire trial.

Supplemental file 2: Statistical results. Statistical results of the linear mixed-effects models, concerning parameters recorded after 36 weeks of feeding.

Supplemental file 3: ARRIVE Checklist.

Supplemental file 4: MIAME Checklist. 

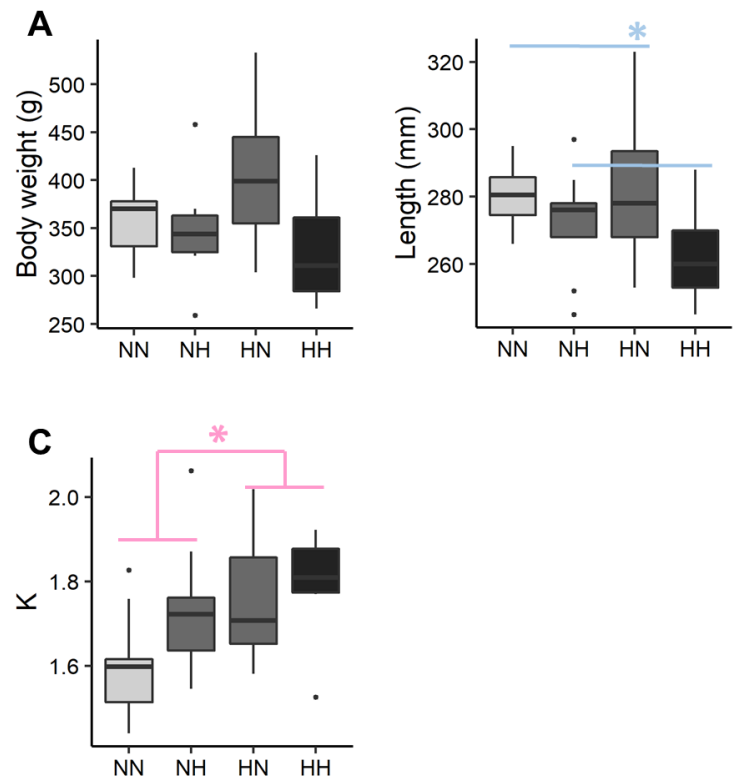

Figure 2. Zootechnical parameters. After 36 weeks of feeding, (A) individual body weights, (B) length and (C) the Fulton's condition factor ( $\mathrm{K}$ index) of the sampled fish ( $\mathrm{n}=9$ per condition) have been analysed by a linear mixed-effects models. Significant differences due to the maternal HC/LP diet (red) and the paternal HC/LP (blue) are represented with stars (P-value $\leq 0.05{ }^{\prime}{ }^{\prime}$ )

\section{ACKNOWLEDGMENTS}

\section{REFERENCES}

Callet, T., Dupont-Nivet, M., Cluzeaud, M., Jaffrezic, F., Laloë, D., Kerneis, T., Labbé, L., Quillet, E., Geurden, I., Mazurais, D., Skiba-Cassy, S., and Médale, F. (2018). Detection of new pathways involved in the acceptance and the utilisation of a plant-based diet in isogenic lines of rainbow trout fry. Plos one, 13(7): 0201462.

Callet, T., Hu, H., Larroquet, L., Surget, A., Liu, J., Plagnes-Juan, E., Maunas, P., Turonnet, N., Mennigen, J. A., Bobe, J., Burel, C., Corraze, G., Panserat, S., and Marandel, L. (2020). Exploring the impact of a low-protein high-carbohydrate diet in mature broodstock of a glucose-intolerant teleost, the rainbow trout. Frontiers in physiology, 11:303.

Congleton, J. and Wagner, T. (2006). Blood-chemistry indicators of nutritional status in juvenile salmonids. Journal of fish biology, 69(2):473-490.

Desai, M., Crowther, N., Ozanne, S., Lucas, A., and Hales, C. (1995). Adult glucose and lipid metabolism may be programmed during fetal life. Biochemical Society transactions, 23(2):331-335.

Finger, B. J., Harvey, A. J., Green, M. P., and Gardner, D. K. (2015). Combined parental obesity negatively impacts preimplantation mouse embryo development, kinetics, morphology and metabolism. Human Reproduction, 30(9):2084-2096.

Folch, J., Lees, M., and Stanley, G. S. (1957). A simple method for the isolation and purification of total lipides from animal tissues. Journal of biological chemistry, 226(1):497-509.

Good, C. A., Kramer, H., and Somogyi, M. (1933). The determination of glycogen. Journal of Biological Chemistry, 100:485-491.

Guo, T., Luo, F., and Lin, Q. (2020). You are affected by what your parents eat: Diet, epigenetics, transgeneration and intergeneration. Trends in Food Science \& Technology.

Hemre, G.-I., Mommsen, T. P., and Krogdahl, Å. (2002). Carbohydrates in fish nutrition: effects on growth, glucose metabolism and hepatic enzymes. Aquaculture nutrition, 8(3):175-194.

Hoffman, D. J., Reynolds, R. M., and Hardy, D. B. (2017). Developmental origins of health and disease: 
A

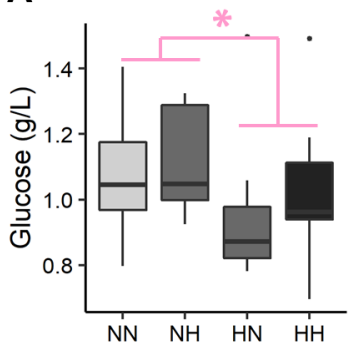

B

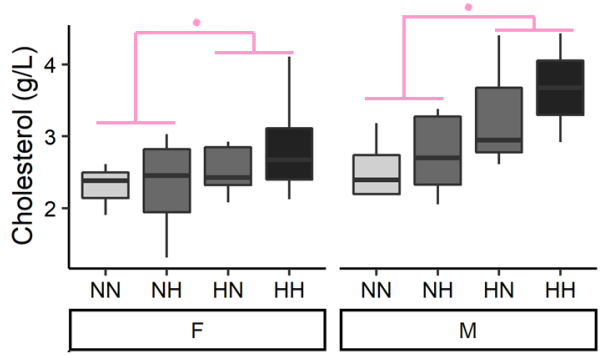

C

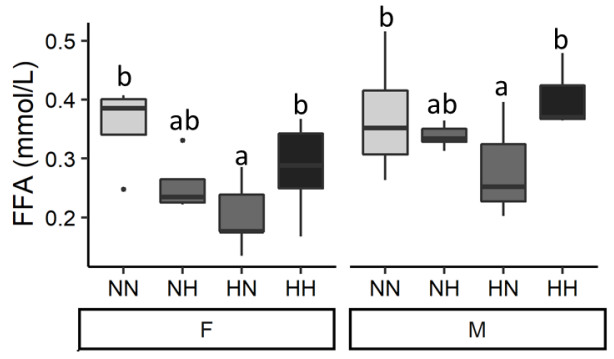

D

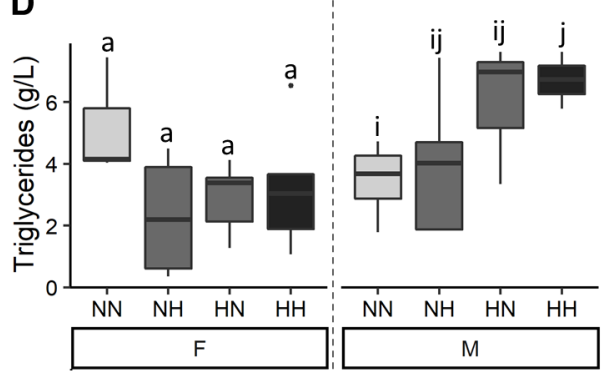

Figure 3. Plasma metabolites. (A) glucose, (B) cholesterol, (C) free fatty acids (FFA) and (D) triglycerides levels in plasma of the sampled fish ( $\mathrm{n}=9$ per condition) after 36 weeks of feeding. Except for plasma glucose concentrations, data are presented for offspring males $(\mathrm{M})$ and females $(\mathrm{F})$ as there was a significant effect of the offspring sex. Significant differences due to the maternal HC/LP diet are represented in red with stars (P-value $\leq 0.10^{\prime}$ '. and value $\leq 0.05^{\prime}{ }^{\prime}$ '). Different letters indicate significant differences between groups, which were investigated with a Tukey post-hoc test.

current knowledge and potential mechanisms. Nutrition reviews, 75(12):951-970.

Hou, Z. and Fuiman, L. A. (2020). Nutritional programming in fishes: insights from mammalian studies. Reviews in Fish Biology and Fisheries, 30(1):67-92.

Jobling, M. (2012). National Research Council (NRC): Nutrient requirements of fish and shrimp. Springer. Kolditz, C., Borthaire, M., Richard, N., Corraze, G., Panserat, S., Vachot, C., Lefèvre, F., and Médale, F. (2008). Liver and muscle metabolic changes induced by dietary energy content and genetic selection in rainbow trout (oncorhynchus mykiss). American Journal of Physiology-Regulatory, Integrative and Comparative Physiology, 294(4):R1154-R1164.

Kroon, F., Streten, C., and Harries, S. (2017). A protocol for identifying suitable biomarkers to assess fish health: A systematic review. PloS one, 12(4):e0174762.

Langley, S. C., Browne, R. F., and Jackson, A. A. (1994). Altered glucose tolerance in rats exposed to maternal low protein diets in utero. Comparative Biochemistry and Physiology Part A: Physiology, 109(2):223-229.

Langley-Evans, S. C. (2009). Nutritional programming of disease: unravelling the mechanism. Journal of anatomy, 215(1):36-51.

Matzkin, L. M., Johnson, S., Paight, C., Bozinovic, G., and Markow, T. A. (2011). Dietary protein and sugar differentially affect development and metabolic pools in ecologically diverse drosophila. The Journal of nutrition, 141(6):1127-1133.

Matzkin, L. M., Johnson, S., Paight, C., and Markow, T. A. (2013). Preadult parental diet affects offspring development and metabolism in drosophila melanogaster. PLoS One, 8(3):e59530.

McPherson, N. O., Bell, V. G., Zander-Fox, D., Fullston, T., Wu, L. L., Robker, R. L., and Lane, M. (2015). When two obese parents are worse than one! impacts on embryo and fetal development. American Journal of Physiology-Endocrinology and Metabolism, 309(6):E568-E581.

Naylor, R. L., Hardy, R. W., Bureau, D. P., Chiu, A., Elliott, M., Farrell, A. P., Forster, I., Gatlin, D. M., Goldburg, R. J., Hua, K., and Nichols, P. D. (2009). Feeding aquaculture in an era of finite resources. 
Proceedings of the National Academy of Sciences, 106(36):15103-15110.

Ornellas, F., Carapeto, P. V., Aguila, M. B., and Mandarim-de Lacerda, C. A. (2019). Sex-linked changes and high cardiovascular risk markers in the mature progeny of father, mother, or father and mother together consuming a high-fructose diet. Nutrition.

Ornellas, F., Souza-Mello, V., Mandarim-de Lacerda, C. A., and Aguila, M. B. (2016). Combined parental obesity augments single-parent obesity effects on hypothalamus inflammation, leptin signaling (jak/stat), hyperphagia, and obesity in the adult mice offspring. Physiology \& behavior, 153:47-55.

Ozanne, S. E. and Hales, C. N. (2002). Early programming of glucose-insulin metabolism. Trends in Endocrinology \& Metabolism, 13(9):368-373.

Prabu, E., Felix, S., Felix, N., Ahilan, B., and Ruby, P. (2017). An overview on significance of fish nutrition in aquaculture industry. International Journal of Fisheries and Aquatic Studies, 5(6):349-355.

$\mathrm{R}$ Core Team (2013). R: A language and environment for statistical computing. R Core Team.

Rando, O. J. (2012). Daddy issues: paternal effects on phenotype. Cell, 151(4):702-708.

Rando, O. J. and Simmons, R. A. (2015). I'm eating for two: parental dietary effects on offspring metabolism. Cell, 161(1):93-105.

Ritchie, M. E., Phipson, B., Wu, D., Hu, Y., Law, C. W., Shi, W., and Smyth, G. K. (2015). limma powers differential expression analyses for rna-sequencing and microarray studies. Nucleic acids research, 43(7):e47-e47.

Song, X., Marandel, L., Skiba-Cassy, S., Corraze, G., Dupont-Nivet, M., Quillet, E., Geurden, I., and Panserat, S. (2018). Regulation by dietary carbohydrates of intermediary metabolism in liver and muscle of two isogenic lines of rainbow trout. Frontiers in physiology, 9:1579.

Tarrade, A., Panchenko, P., Junien, C., and Gabory, A. (2015). Placental contribution to nutritional programming of health and diseases: epigenetics and sexual dimorphism. Journal of Experimental Biology, 218(1):50-58.

Vijayan, M. and Moon, T. (1992). Acute handling stress alters hepatic glycogen metabolism in fooddeprived rainbow trout (oncorhynchus mykiss). Canadian Journal of Fisheries and Aquatic Sciences, 49(11):2260-2266.

Watkins, A. J., Dias, I., Tsuro, H., Allen, D., Emes, R. D., Moreton, J., Wilson, R., Ingram, R. J., and Sinclair, K. D. (2018). Paternal diet programs offspring health through sperm-and seminal plasmaspecific pathways in mice. Proceedings of the National Academy of Sciences, 115(40):10064-10069.

Watkins, A. J., Rubini, E., Hosier, E. D., and Morgan, H. L. (2020). Paternal programming of offspring health. Early Human Development, page 105185.

Yano, A., Nicol, B., Jouanno, E., Quillet, E., Fostier, A., Guyomard, R., and Guiguen, Y. (2013). The sexually dimorphic on the y-chromosome gene (sdy) is a conserved male-specific y-chromosome sequence in many salmonids. Evolutionary applications, 6(3):486-496.

Zambonino-Infante, J., Panserat, S., Servili, A., Mouchel, O., Madec, L., and Mazurais, D. (2019). Nutritional programming by dietary carbohydrates in european sea bass larvae: Not always what expected at juvenile stage. Aquaculture, 501:441-447.

Zheng, S., Rollet, M., and Pan, Y.-X. (2012). Protein restriction during gestation alters histone modifications at the glucose transporter 4 (glut4) promoter region and induces glut4 expression in skeletal muscle of female rat offspring. The Journal of nutritional biochemistry, 23(9):1064-1071.

Zohdi, V., Lim, K., Pearson, J. T., and Black, M. J. (2015). Developmental programming of cardiovascular disease following intrauterine growth restriction: findings utilising a rat model of maternal protein restriction. Nutrients, 7(1):119-152. 
A
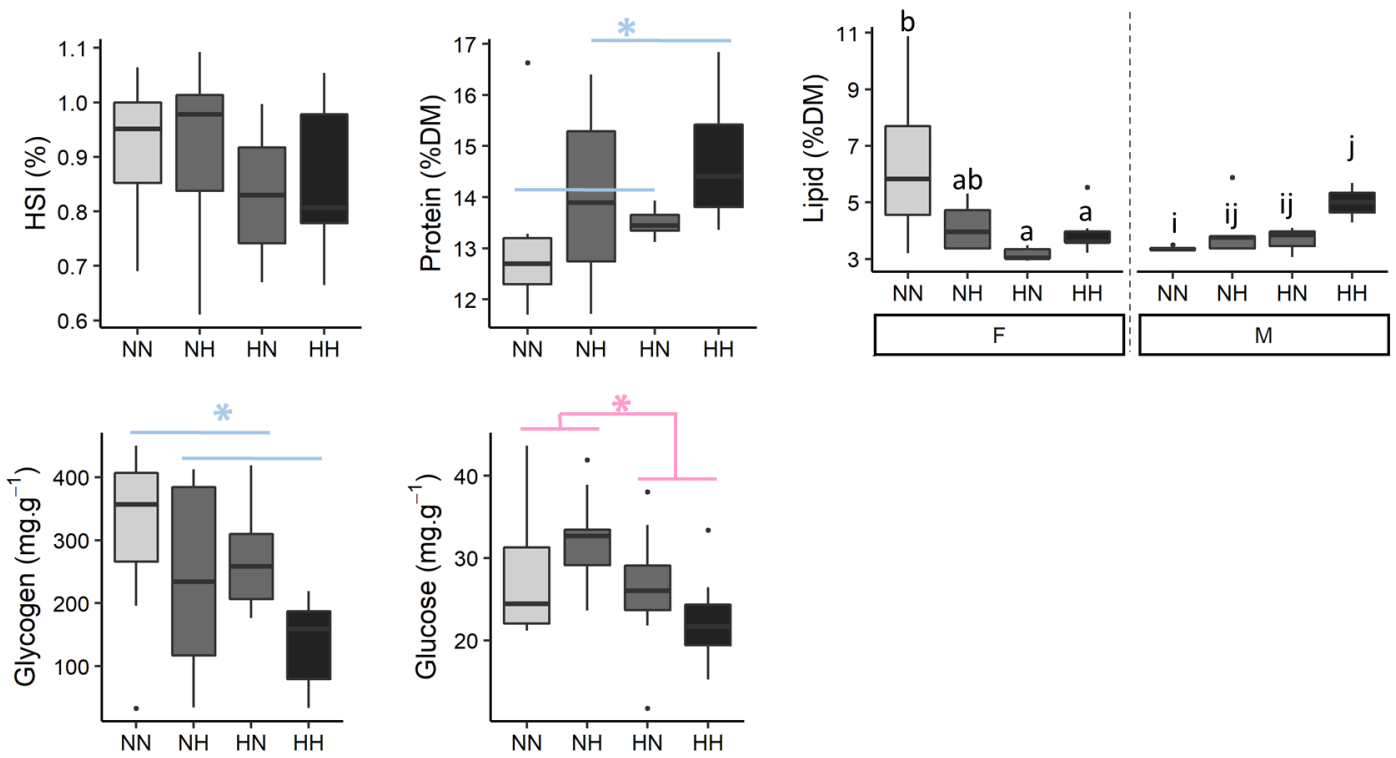

B
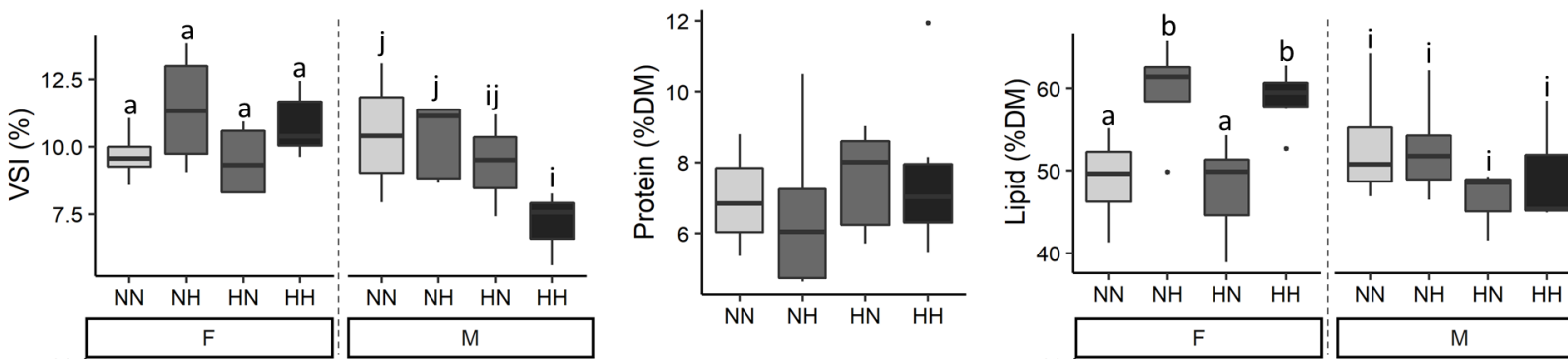

C
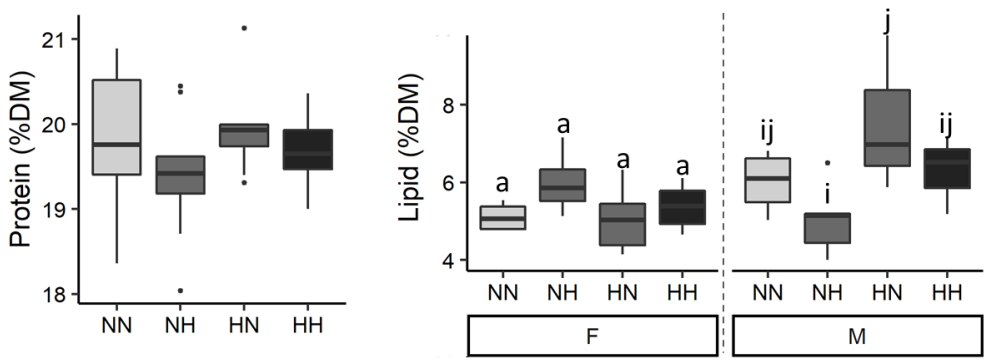

Figure 4. Tissue biochemical composition. The biochemical composition of (A) liver, (B) viscera and (C) muscle of the sampled fish ( $\mathrm{n}=9$ per condition) after 36 weeks of feeding. Data are presented for offspring males (M) and females (F) when there was a significant effect of the offspring sex. Significant differences due to the maternal HC/LP diet (red) and the paternal history (blue) are represented with stars $\left(\mathrm{P}\right.$-value $\leq 0.05^{\prime}{ }^{\prime}$ '). Significant interactions were investigated with a Tukey post-hoc test (significant differences are indicated with different letters) 